\title{
Interpreting People's Behavior Toward Primates Using Qualitative Data: a Case Study from North Morocco
}

\author{
Siân Waters ${ }^{1,2}$ (D) Ahmed El Harrad ${ }^{2} \cdot$ Sandra Bell $^{1}$. \\ Joanna M. Setchell ${ }^{1}$
}

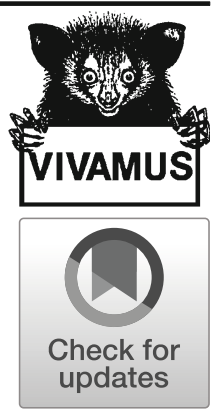

Received: 16 August 2018 / Accepted: 8 March 2019 / Published online: 1 May 2019

(C) The Author(s) 2019

\begin{abstract}
People's perceptions of primates vary across and within cultures and may not be consistent with their behavior toward the primates themselves. We used qualitative data from semistructured and unstructured interviews with shepherds from 10 villages around Bouhachem oak forest in Morocco to describe and discuss shepherds' behavior when they encounter Barbary macaques (Macaca sylvanus). When macaques enter agricultural fields to feed on crops, mature men trap, attach a marker to them (a hat or a rattle), and release them. In contrast, young men and boys working as shepherds hunt and kill macaques when they encounter them in the forest. We interpret these findings in the context of the historical, social, and cultural factors that underlie these crossspecies encounters. We suggest the different ways men behave toward macaques over their lives are related to their age and social status. Understanding that men's behavior varies, and changes over the life course, we continued to engage positively with shepherds of all ages, sharing general information about the macaques and conducting community projects benefiting villagers' health. This strategy led shepherds from six villages to stop hunting macaques, with the behavior of young men and boys changing to reflect that of older men. We suggest that gaining a deep, contextualized understanding of the human-primate interface and fostering intrinsic values for a species are effective in gaining communities' support and fundamental to facilitating changes in people's behavior in favor of conservation.
\end{abstract}

Keywords Community conservation · Conservation · Crop feeding · Hunting · Macaques · Morocco $\cdot$ Shepherds

Handling Editor: Jessica Rothman

Siân Waters

sian.s.waters@durham.ac.uk

1 Department of Anthropology, Durham University, Durham DH1 3LE, UK

2 Barbary Macaque Awareness and Conservation Tétouan, Tetouan, Morocco 


\section{Introduction}

Physical encounters between people and wildlife can have unpredictable and often negative consequences for wildlife (Cassidy and Mills 2013; Hill 1997; Knight 2003; Treves 2008). Species are valued, vilified, or killed for complex social, cultural, economic, or political reasons (Dickman et al. 2014; Dore 2018; Richards 2000). Moreover, how people view a species does not necessarily predict their behavior toward it (Delibes 2013; St John et al. 2010). For example, communities living close to a ecotourism conservation project in Trinidad perceived hunting as a major threat to wildlife but continued to hunt for recreation (Waylen et al. 2009).

People's perceptions of primates can be particularly complex because of their similarity to humans. Primates are liminal, neither human nor animal but something in between (Costa et al. 2013; Dore et al. 2018; Waters et al. 2018a). Many primate species come into contact with people in diverse situations and with varying consequences (Dore et al. 2018; Hofner et al. 2018; McKinney 2015; Thach et al. 2018). Human-primate interactions are influenced by diverse cultural, social, ecological, and other components that may be unique to geographical regions and are fundamental to the continued existence of remaining primate populations (Dore 2017; Hill and Webber 2010; Lee and Priston 2005; Parathian et al. 2018; Waters et al. 2018a). Many negative human-primate interactions are underpinned by social or political conflicts where, for example, marginalized people consider wildlife to be the state's responsibility and hold it responsible for the losses they incur to their livelihoods (Anand et al. 2018; Margulies and Karanth 2018). This perception is particularly common among people living around protected areas or where the state excludes local people from forest or wildlife management. In effect, these are human-human conflicts where protected wildlife species, such as primates, symbolize people's discontent with the status quo (Hill 2005; Hill et al. 2017; Madden and McQuinn 2014).

Macaques (Macaca sp.), with their expansive ranges, large group sizes, and omnivorous, adaptable diets, frequently come into contact with people in diverse contexts such as the pet trade, hunting, and tourism (Bergin et al. 2018; Marechal et al. 2016; Peterson and Riley 2013). Some macaque species are commensal with people because of their ability to live in heavily anthropogenically altered environments (Richard et al. 1989; Wheatley et al. 2002). Many Asian macaque species regularly enter agricultural fields (Anand et al. 2018; Hill 2017; Knight 2003). This behavior is commonly referred to as crop-raiding but because of the negative connotations associated with that term, we follow other researchers' recommendations and refer to it as crop-foraging or crop feeding (Hill 2015; Hockings et al. 2015).

Complex factors such as cultural beliefs, values and customs, economics, and politics can play a large part in whether people tolerate crop-foraging macaques (Peterson et al. 2015; Riley 2007; Saraswat et al. 2015). For example, a group of indigenous farmers in Sulawesi whose culture emphasizes the interconnectedness of people and nature tolerate Tonkean macaques (Macaca tonkeana) and do not kill them in retaliation for crop-foraging (Riley 2010). Long-tailed macaques (M. fascicularis) around temples in Bali are regarded as sacred and fed by visitors, but when the macaques venture outside temple areas into neighboring fields, they are persecuted and sometimes shot (Schilaci et al. 2010). Introduced long-tailed macaques on Ngeaur Island, Republic of Pilau, are trapped and shot by islanders partly because of their 
negative associations with the former colonialists who introduced the species (Wheatley et al. 2002). In Himachal Pradesh, northern India, farmers' religious beliefs prevented them from killing crop-foraging rhesus macaques ( $M$. mulatta) although the state paid a bounty for each animal killed (Anand et al. 2018). Such complexity surrounding the human-macaque interface in Asia illustrates why understanding people's interpretations of primates in their shared environment (known as ontology in sociocultural anthropology) is an important first step in understanding how they react to the animals when in close proximity to them (Knight 2017).

The Barbary macaque (Macaca sylvanus) is the only macaque found in Africa and is Endangered due to habitat destruction and degradation and illegal poaching of infants for the pet trade (Butynski et al. 2008). Barbary macaques have been exploited for trade throughout the Mediterranean and the UK since at least Roman times (Goudsmit and Brandon-Jones 2000) and were first reported to forage on crops by Leo Africanus in the early sixteenth century (Fooden 2007). In the western High Atlas Mountains in Morocco, crop-foraging macaques are reportedly killed by farmers in the Ourika valley (Namous and Znari 2018), and retribution for crop feeding was suggested as an explanation for why shepherd boys and their dogs hunted and killed Barbary macaques in the Ghomara region of north Morocco (Mehlman 1984).

We began an inclusive conservation project to improve prospects for the Barbary macaque in Bouhachem forest in north Morocco in 2009. Our primary aim was to engage with and include shepherds in conservation activities because they were in the forest for most of the year and encountered Barbary macaques regularly. Our interviews with shepherds provided us with important insights into their views and perceptions of Barbary macaques and other animals that we have used to develop conservation strategy to actively recruit local community members into conservation activities (Waters et al. 2018a).

Here, we report on the context of physical interactions between humans and Barbary macaques in Bouhachem forest. The Barbary macaque holds an ambiguous position in many shepherds' understandings, where the dualist categories of humans and animals, nature and culture are indivisibly entwined (Waters et al. 2018a). Despite the religious belief expressed by some shepherds that the macaques were metamorphosed humans, they did not mention any taboos against killing the animals (Waters et al. 2018a). Here, we describe how this ambiguity is embodied in shepherd-macaque relationships using shepherds' accounts of how they interact physically with Barbary macaques in both agricultural and forest spaces in Bouhachem. We report our findings regarding local people's reactions to crop feeding by Barbary macaques in Bouhachem and describe how men change the appearance of macaques and release, rather than kill them, in their attempts to deter the animals from entering fields. We continue by relating how Barbary macaques are treated in the forest when young shepherds use their dogs to hunt, capture, and kill them in a negative cross-species encounter. We suggest that the shepherds' behavior toward the macaques is dynamic, changing with a shepherd's age and related to the shepherd's own position in village society. Over a period of time during the process of sharing information with the farmer-shepherds and listening to their explanations of their interactions with macaques we also witnessed alterations in attitudes and behaviors favorable to the conservation of Barbary macaques. 


\section{Methods}

\section{Study Site}

Our study site is Jbel Bouhachem Nature Reserve, which we refer to as Bouhachem hereafter. Bouhachem is a remote mountainous area of ca. $142 \mathrm{~km}^{2}$ in north Morocco. The mixed oak forest is an important source of water and nontimber forest products for surrounding villages as well as home to the Barbary macaque and other wildlife. The forest was exploited intensively for its timber during the last years of the Spanish occupation which ended in 1956 (El Abdellaoui 1999). Ten villages are adjacent to or directly on the edge of the forest. Crops planted by villagers include corn, vegetables, and fruit. Villagers rely on their goat (Capra hircus) herds for financial security. Shepherds, accompanied by livestock guarding dogs (Canis lupus familiaris), herd goats into and out of the mountains daily, returning them to their villages before dusk.

\section{Data Collection}

Our study participants were all men working as shepherds and of the Sunni Muslim sect of Islam. We present data from both semistructured and unstructured interviews that we used to ensure the participants felt in control and positive about the interaction when talking about sensitive subjects. We collected semistructured interview data from March to November 2010 with a break in August 2010 for Ramadan. We interviewed five shepherds aged 14-84 years from each of the 10 villages situated on the periphery of Bouhachem forest while conducting Barbary macaque survey work in the forest. During the interviews, which focused on Barbary macaque locations, many shepherds talked about their past interactions with Barbary macaques and commented on the activities of other shepherds. We collected additional data from unstructured interviews during further engagement with 26 shepherds in April and May 2011.

\section{Data Analysis}

The first author's (SW) grasp of Arabic was very basic and she conducted interviews via her research assistant A. All interviews were recorded and SW and A translated and transcribed them into English, checking an Arabic/English dictionary for accuracy if necessary. It is likely, however, that we lost some information or nuance during these translations and transcriptions. SW explored each transcript, noting emerging themes and placing them in coded categories. SW also kept field notes that proved useful for identifying the themes emerging from the engagements with local men. Our analysis thus followed an iterative grounded approach in which we used open coding to further analyse and identify emerging themes based on the qualitative data as opposed to identifying them beforehand (Tadie and Fischer 2013) and we continued the analysis until these themes became stable (Cassidy 2017). We selected quotes and parts of conversations to provide a consistent and coherent narrative with which to support our analysis of the data.

Data Availability The datasets analyzed during the current study are available from the corresponding author on reasonable request. 


\section{Ethical Note}

At the start of each interview we explained the study to each shepherd and asked him if he would like to participate in it. No one refused. All participants remain anonymous. This project gained approval from the Research Ethics and Data Protection Committee of the Department of Anthropology, Durham University, in spring 2009. The authors declare they have no conflict of interest.

\section{Results and Interpretation}

\section{Human-Macaque Relationships in the Fields}

During the semistructured interviews, shepherds from five villages told us that Barbary macaques foraged in their wheat fields and fruit trees. Shepherds from the remaining five villages said that their fields were too far from the forest $(>1 \mathrm{~km})$ to be accessible to macaques. All shepherds who mentioned macaque crop foraging stated that it took place in June and July, just before the crops were ready for harvesting and when fruit was ripening. Most of these men acknowledged there was little food for the macaques in the forest until mid-August, when Pyrenean oaks (Quercus pyrenaica) began producing acorns, which the macaques eat. For instance:

The macaques are hungry in summer. They start coming down more often to look for food. When they are really hungry they come right down to the house because we have fruit trees nearby. They stay in the forest for the rest of the year.

Anonymous, 25 years, Slalem

The fields of the five villages where macaque crop foraging occurred were accessible to the macaques for various reasons. In four villages, villagers cultivated fields on the forest edge or in the forest itself; in one village, they cultivated fields close to a forested canyon, which provided a corridor for macaques to access crops. We observed a macaque group foraging in fields adjacent to the forest boundary only once. We saw an adult male feeding in a potato field with other group members foraging in the field closer to the forest edge. The animals moved back into the forest when they saw us.

Shepherds perceived dogs as the main deterrent against crop-foraging macaques but they also used traps to catch wildlife visiting crop fields. Six shepherds from four different villages recounted a similar story of how they dealt with macaques they had trapped. They did not kill the trapped animal but changed its appearance by attaching a hat or a rattle to it to differentiate it from the other macaques, and then released it. For example:

We catch a macaque and sew a hat on its head or put a tin can round its neck with stones in it to make it rattle, so that the other monkeys, when they see him, run off. We let the macaque go and he runs after the others but they run faster than him because they are frightened of him.

Anonymous, 45 years 
The shepherds found it amusing to recount how the macaque ran after its group as the group, in turn, ran away from an unusual individual. Their apparent amusement at this practice could have been an attempt to hide their unease about the plight of the solitary macaque always running after its group. Villagers clearly understood that the macaque was avoided by conspecifics. For example, one man told me:

One of my neighbors trapped a monkey in his wheat field and put a can around its neck filled with stones. When I was working in the forest, I used to hear the can before I saw the monkey. The macaque could feed itself even with the can around its neck but it was always about $200 \mathrm{~m}$ from its group. I felt sorry for it - always alone. Monkeys like to be together but this one's family didn't recognise it anymore.

We could not determine whether crop foraging decreased as a result of the attempted deterrents but it is difficult to deter other macaque species from crop foraging (Hardwick et al. 2017; Linkie et al. 2007). For example, bonnet macaques quickly learned to avoid a hunter who was selectively shooting members of their group on visits to forage in plantations in South India (Chakravarthy and Thygaraj 2005).

Barbary macaques are the only crop-foraging species in Bouhachem that people trap and release. Wild boar (Sus scrofa) share primates' status as metamorphosed humans in Islam (Foltz 2006) and feed on and damage villagers' crops in Bouhachem. Villagers regularly report wild boar crop feeding to the forestry authorities, who issue permits for hunters to cull the animals. The authorities were unaware of the problems caused by crop-feeding macaques in Bouhachem and there is no official strategy to deal with the situation in the region.

Mature men's reluctance to kill the macaques may relate to their recognition of the macaques as similar to people. For example, an older shepherd told me: "If you kill a macaque, it's as if you have killed a man." Like the macaques, villagers also have difficulty finding enough water and food for their livestock in summer, which may foster their empathy for macaques forced out of the forest to feed on crops. However, the macaques' anomalous nature may also encourage men to believe that marking the animals and releasing them deters them from reoffending.

Our study provides an example of how people mitigate negative interactions with wildlife without killing it. The men's behavior suggests that they believe the macaques' behavior is intentional. In other words, the men believe that the macaques have agency, so give the macaques the opportunity to learn not to transgress further. Their perceptions of Barbary macaques as agentive beings echo those of subsistence farmers of St. Kitts, who perceived crop foraging vervet monkeys (Chlorocebus sabaeus) as "minded" (Dore et al. 2018). Subsistence farmers of Ngeaur Island, Palau held a similar view of crop foraging long-tailed macaques (Wheatley et al. 2002) although both these farmer groups admitted to killing the animals (Dore et al. 2018; Wheatley et al. 2002).

We found two documented cases of farmers marking and releasing rather than killing primates for crop foraging elsewhere. In Ethiopia, farmers captured a group of monkeys (of an unidentified species) and painted each individual a different color before releasing them, allegedly never to be seen again (Dixon et al. 2009). In a media report from South Africa, a vervet monkey (Chlorocebus aethiops) is pictured covered in paint. The same report attributes old farmers with the practice of catching a monkey and covering it in a paste of water and flour with the idea that the animal would be followed away from the fields by its group (Venktess 2015). 
Elsewhere in Morocco, farmers in the Ourika valley in the High Atlas Mountains kill crop-foraging macaques (Namous and Znari 2018) and blame the national park authorities for not controlling the macaques' behavior because of its protected status (Gray 2014). Such human-human conflicts are common around state-managed protected areas and/or species when communities feel excluded from management strategy (Bell et al. 2008; Madden and McQuinn 2017; Sprague and Draheim 2015). At our study site, villagers do not report macaque crop foraging to local wildlife authorities, suggesting there are no human-human conflict issues relating to the macaques.

\section{Human-Macaque Relationships in the Forest}

Four elderly shepherds described how the Spanish captured young macaques and exported them to Spain for sale as pets and to zoos during the occupation. All the men said that many macaques were killed during these drives, which took place "frequently" during spring and summer. Mr. K., who was 83 years old when we spoke with him, described what happened:

The Spanish boss would tell us to get macaques...There was a short period between each macaque trapping session but they occurred frequently. There were lots of people and dogs and many macaques were killed by dogs. The little ones were taken by the Spanish to sell to zoos.

During our interviews with men $>35$ years, they sometimes recounted incidents of purposely persecuting and killing macaques for fun when they were younger, and some referred to the continued existence of this practice. For instance, Mr. M. said "People kill them [the macaques] and they haven't done anything." Mr. B., a mature shepherd, told us that he had participated in such an event 17 years previously, before he was married and became a parent. He told us he stopped when he married "because it was wrong and goes against what is written in the Qur'an."

We never witnessed people killing macaques, probably because of the illicit and opportunistic characteristics of such killings, and the shepherds doing the hunting never mentioned it to us while they continued the practice. However, in spring 2011, during an unstructured interview with 27-year-old A., he revealed that he had recently killed macaques for fun. A. made it clear that he and the other participants knew that what they were doing was illegal. He described what happened when a macaque group was encountered:

A.: The young boys starting work as shepherds bother macaques daily even though they know it is against the law. They aren't always successful but they get about one macaque a month. [Begins to use plural pronouns and past tense] When we saw macaques, we called the dogs together and encouraged them to harass the monkeys. When the macaques were in a tree, we cut the branches to stop them escaping and encouraged the dogs to bark so when the macaque fell the dogs would catch it. When it was a big macaque, the dogs killed it. We would get the small ones off the dogs and play with them then return them to the dogs to finish off. Interviewer: What did the other macaques do? 
A.: The macaques always began to scream before we did anything, and when we got one they would move away from the scene but keep screaming. If they saw a dead one, they would form a group and move away from the site. They would scream for about 20 minutes.

We doubted that the macaques "fell" out of the tree without some sort of assistance and indeed an older man revealed that:

If the macaques went into the tree and stayed there, we surrounded the tree and pelted the macaques really hard with rocks.

In this scenario, the macaques fell to the ground, incapacitated by the youths' rock pelting and were then extremely vulnerable to attack from the waiting dogs. The event was a negative cross-species encounter where dogs were pitted against adult macaques. Youths deliberately removed the smaller macaques from the dogs and, according to one previous practitioner, he and other youths would:

Shake them [the macaques], break their limbs and try to make them talk and after they became unconscious we returned them to the dogs.

Anonymous, 24 years

We asked A. if he thought the macaques felt the loss of a group member. His answer was emphatic:

Absolutely, they feel the loss absolutely-like people do-you know? When we get older we don't give any importance to hunting the macaques. You aren't going to get anything if you attack one. Men don't take any notice of macaques. When we grow up we have more feelings.

In this statement, A. acknowledged the similarity in the sociality of macaques and people and recognized the loss that death brings to both. His remark that sensitive feelings come with maturity accords with Mr. B.'s statement that when he got married and had a family he stopped hunting the macaques. Young shepherds needed to ensure adequate nutrition for the goats, which represented their families' or villages' accumulated wealth. However, this meant spending long periods of time in the wild space of the forest, thus occupying a world spanning both wild and domestic spheres, possibly making the shepherds liminal in villagers' perceptions. In the forest, they were free of the social restrictions and boundaries that inhibited their village life, and established certain distinctions between them and the animal kingdom.

One 6-year-old boy told us he hated seeing the macaques killed but the older boys forced him to go with them, making him complicit in the activity. A shepherd corroborated this when he said:

Shepherds learn this behavior from one generation to the other. The older ones stop but they have already taught the habit to the younger ones who then continue doing it.

Anonymous, 27 years 
Some mature shepherds seemed to find the practice inexplicable because of the macaques' resemblance to people and one stated:

I couldn't bother them but there are people who bother them. Why do they bother them, the poor things? They are like us.

Anonymous, 80 years

Our discussions with shepherds lead us to suggest that the point when a shepherd stops participating in the practice of macaque hunting relates to his marital status. Although boys and young men are responsible for the family herd, they perceive their job as low status. They often begin working as shepherds from 8 to 14 years. Some boys may leave school early, as they are more useful tending the goats than they are at school. Young men attain adult status when they marry at around the age of 25-30 years. A married man is "promoted" to working the land and caring for his family. Marriage and family life place married men in the human space of the village, with all the social interactions and recognition of kin relationships and responsibilities that involves. A man $>50$ years returns to shepherding if his children have left the village. Many young men express discontent with their lives as shepherds, but they have no opportunity to train for alternative employment because many of them are illiterate as a result of not completing their education. A. is one such young man. He said:

I can't do anything else. I am not happy, I do it [shepherding] with an effort. I am always in the forest and I don't see anybody except the other shepherds.

A. estimated that shepherds killed about one macaque per month whereas another shepherd from the same village said that by the time the boys had finished, the ground would be littered with dead macaques. The reality probably lay somewhere in between but even lowintensity hunting pressure can be enough to negatively affect primate densities (Marshall et al. 2006). The conservation team observed Barbary macaque groups moving silently through the forest away from goat herds and their accompanying shepherds and dogs suggesting they have learned this cryptic behavior to avoid persecution.

We inferred from the reluctance of many shepherds to admit to or discuss their past macaque hunting behavior that their own religious and moral code meant that they were aware that the suffering they inflicted on the macaques was wrong. However, in the forest, away from the social controls of village life, religious tenets were easily forgotten and social group norms prevailed. The shepherds straddled boundaries, inhabiting the borderlands between wild and domestic space, while socially they were considered neither adults nor children occupying an ambiguous, and low status position in village society.

It is hard to ascertain if young shepherds had always hunted and killed the macaques or if their forebears acquired the practice during the Spanish occupation when macaque drives appeared to be commonplace and motivated by commercial gain.

\section{Changing Behavior}

Our sustained, positive engagement with shepherds enabled them to admit to us that they had killed macaques in the past. Our discussions with shepherds suggest that macaque killing becomes unacceptable with maturity, but that mature men did not feel 
strongly enough to openly condemn boys for conducting the activity. We used this understanding to encourage a change in behavior among young shepherds.

Macaques are a protected species in Morocco and killing them without relevant permits is illegal. Seeking legal avenues or mitigation methods to change men's behavior toward the macaques might have led to shepherds being fined for their behavior. We did not pursue these options because we did not want to risk destroying the trust we had built up with the shepherds. Instead, we focused on positive engagement with them and began sharing information about Barbary macaques, such as their limited distribution in North Africa, and in Morocco in particular, along with their ecological role in the forest. This information engaged the shepherds and led many of them to think about the macaques in a different and more positive way. This change led some of them to admit to us that they had previously killed macaques but had stopped in response to our positive contacts with them and our respectful treatment of their opinions and knowledge. For example:

Before you came, we didn't realize how much we knew about the macaques and now we know that they too have their job in the forest and that [knowledge] is important and in the interests of everyone, people and animals.

Some also began to speak out against the practice of macaque killing by shepherds, making it socially unacceptable in their peer group. These shepherds made macaque conservation, rather than macaque hunting, socially legitimate among their peers and established themselves as role models to encourage shepherds to voluntarily stop macaque hunting. In October 2010, a shepherd from one village told me that because of our regular visits, boys in his village no longer persecuted the macaques:

There are many boys who have become more educated and don't go torturing or killing the macaques. They don't bother them anymore because they see you a lot. Before you came, they used to kill a lot of macaques with their dogs. They have changed and talk a lot about the macaque people who come to visit them in the forest. Last year I know more than six macaques were killed by boys and their dogs and now they [the boys] feel very sorry that they did that. The animals don't do anything and it's not right to torture them.

Some of the older shepherds began to take a lead in making macaque hunting socially unacceptable. For example, when one encountered a group of boys persecuting macaques, he intervened and expressed his disapproval. He told us:

I took the baby off them and told them they should be ashamed. Its mother came back and called for it so I put it in a tree and moved away and as I moved away its mother came and got it.

Another shepherd expressed the view that shepherds needed to share their information with peer group members and explain why torturing and killing the macaques was unacceptable. He told us: 
I pass my knowledge to other shepherds and tell them it isn't good or right [to attack the macaques]. If one shepherd is informed then he should tell the other shepherds to stop attacking the macaques so they don't disappear from the forest.

To reinforce and support the shepherds' change in behavior, we also provided proactive conflict mitigation initiatives focusing on livestock and people's health in the villages most affected by crop-foraging macaques. For example, we vaccinated village dogs against rabies, which affected both people and livestock in the villages surrounding Bouhachem (Waters et al. 2018b). In 2016, we began to facilitate visits of a health outreach team to remote villages, providing health checks to villagers who were not mobile enough to visit their closest health center. We accompanied these visits with educational activities for villagers to reinforce the connecting links between the activity, the conservation team, and the macaques.

Both social and religious factors facilitated the Bouhachem shepherds' voluntary cessation of Barbary macaque killing. The change was also greatly influenced by our regular encounters with the shepherds and the discussions that ensued. Dialogue and information sharing between the shepherds and ourselves allowed new perspectives concerning the macaques to emerge. Key individual shepherds then enlisted religious tenets and social disapproval to persuade their peers to stop killing macaques. Religious tenets and social disapproval are both important factors in people's attitudes to killing primates. For example, adherence to taboos preventing the killing of Sclater's monkey (Cercopithecus sclateri) was influenced by people's fear of supernatural retribution at one site in southeastern Nigeria, and social disapproval by their community at another, although most people no longer practiced animism, having converted to Christianity (Baker et al. 2014).

\section{Discussion}

In Bouhachem forest, north Morocco, the people-macaque interface was marked by violence toward the macaques although their human persecutors saw macaques as agentive beings. After trapping a crop feeding Barbary macaque, mature men attached a hat or a rattle to the animal and then released it rather than killing it but younger men and boys killed macaques in the forest. These behaviors illustrate how coexistence between people and primates is grounded in local reality. People's perceptions of macaques vary and change as the macaques move in and out of socially constructed categories (Knight 2003; Radford et al. 2018; Saraswat et al. 2015; Yeo and Neo 2010). For example, Singaporeans' perceptions of longtailed macaques ranged from viewing them as human and wanting them to be better behaved to seeing them as dispensable when they continually transgressed human expectations of both territory and behavior (Yeo and Neo 2010). Residents of Gibraltar complained about the behavior of the introduced population of Barbary macaques but also defended the animals against those who wanted to control the population by culling (Radford et al. 2018). In northern India, farmers demanded that crop-foraging rhesus macaques be accorded vermin status, believing it to be the state's responsibility to lethally control the animals despite them having qualms about killing the animals themselves (Anand et al. 2018). 
Altering a primate's appearance rather than killing it clearly satisfies some communities who feel it sufficient to exact retribution for crop foraging. Such behavior may be indicative of emotional coping to reduce stress about wildlife damage and building farmers' tolerance to crop losses (Gogoi 2018). If this is the case then it is impractical and unreasonable to expect these people to stop what they perceive as an effective deterrent (Wallace and Hill 2017) unless a more humane and practical alternative is available.

As conservationists, we characterize the human-primate interface as "an actionable domain and platform for conservation" (Jost-Robinson 2017, p. 254) sometimes leading to inappropriate interventions (Yeo and Neo 2010). The communication of outsiders' ethnocentric repugnance for the shepherds' killing of macaques would have been inappropriate in the cultural and social context of these communities. Negative interactions between people and primates raise moral questions about how to move people's ontologies toward "a more than human one" (Thach et al. 2018, p. 58). Our positive interactions and knowledge sharing with the shepherds changed the narrative around the macaques and our initially divergent discourses became a shared one when some men's views of macaques transformed. This transformation enabled those men interested in the macaques to express that interest among their peers and to favor Barbary macaque protection rather than persecution and encouraged them to make efforts to change the dynamic in the forest from macaque persecution to protection.

\section{Conclusions}

Using qualitative data provides a much more nuanced understanding of humanprimate interactions than quantitative data (Jost-Robinson 2017; Setchell et al. 2017) and can provide guidance on how, or indeed if, to act as practicing conservationists. Our findings contextualise relations between people and primates, and show that these relations are dynamic, varying with the social and cultural mores that affect people's perceptions of primates throughout their lives. We suggest that gaining an ethnographically and contextually grounded understanding of the human-primate interface, not rushing to criticize behavior we find unacceptable, and fostering an intrinsic value for a species may change people's existential understandings of animals, earn people's support, and be fundamental in facilitating changes in behavior that promote conservation.

Acknowledgments S. Waters is indebted to the Royal Zoological Society of Scotland for supporting her research 2009-2012. We thank the Haut Commissariat des Eaux et Forêts et la Lutte Contre le Désertification for granting our research permit and University Abdelmalek Essâadi, Tétouan for assistance with our permit applications. We are extremely grateful to Association Beauval Nature; Association Française des Parcs Zoologiques, France; GaiaZOO, The Netherlands; People's Trust for Endangered Species, UK; Tiergarten Schönbrunn, Austria; Conservatoire pour la protection des primates, France; Folly Farm, UK; Zoo Helsinki, Finland; Parco Natura Viva, Italy; Blair Drummond Safari Park, UK; NaturZoo Rheine, Germany; Alameda Wildlife Conservation Park, Gibraltar; Mohamed Bin Zayed Endangered Species Fund; and many private donors for supporting our research and conservation work. We are very grateful to associate editor Jessica Rothman for handling the manuscript and to Dr. Rothman and two anonymous reviewers for their positive and constructive comments on an earlier version of this manuscript. 
Author Contributions SW developed methodology, analyzed the data, and wrote the manuscript; SW and AEH conducted fieldwork; SB and JMS provided editorial input.

Open Access This article is distributed under the terms of the Creative Commons Attribution 4.0 International

License (http://creativecommons.org/licenses/by/4.0/), which permits unrestricted use, distribution, and reproduction in any medium, provided you give appropriate credit to the original author(s) and the source, provide a link to the Creative Commons license, and indicate if changes were made.

\section{References}

Anand, S., Binoy, V.V., \& Radhakrishna, S. (2018). The monkey is not always a god: Attitudinal differences toward crop-raiding macaques and why it matters for conflict mitigation. Ambio, 47, 711-720.

Baker, L. R., Olubode, O. S., Tanimola, A. A., \& Garshelis, D. L. (2014). Role of local culture, religion, and human attitudes in the conservation of sacred populations of a threatened 'pest' species. Biodiversity and Conservation, 23, 1895-1909.

Bell, S., Hampshire, K., \& Tonder, M. (2008). Person, place and knowledge in the conservation of the Saimaa ringed seal. Society and Natural Resources, 21, 277-293.

Bergin, D., Atoussi, S., \& Waters, S. (2018). Online trade of Barbary macaques Macaca sylvanus in Algeria and Morocco. Biodiversity and Conservation, 27, 531-534.

Butynski, T. M., Cortes, J., Waters, S., Fa, J. E., Hobbelink, M. E., et al. (2008). Macaca sylvanus. The IUCN Red List of Threatened Species. Version 2013.2. http://www.iucnredlist.org/details/12561/0. Accessed 13 June 2017.

Cassidy, A. (2017). Badger-human conflict: An overlooked context for bovine TB debates in the UK. In C. M. Hill, A. D. Webber, \& N. E. C. Priston (Eds.), Understanding conflicts about wildlife (pp. 65-94). Oxford: Berghahn Books.

Cassidy, A., \& Mills, B. (2013). Fox tots attack shock: urban foxes, mass media and boundary-breaching. Environmental Communication, 6, 494-511.

Chakravarthy, A. K., \& Thygaraj, N. E. (2005). Coexistence of bonnet macaques (Macaca radiata Geoffroy) with planters in the cardamom (Elettaria cardomomum Maton) and coffee (Coffea arabica Linneaus) plantations of Karnatka, South India: Hospitable or hostile? In J. D. Paterson \& J. Wallis (Eds.), Commensalism and conflict: the human-primate interface (pp. 270-293). Norman: American Society of Primatologists.

Costa, S., Casanova, C. C. N., Sousa, C., \& Lee, P. (2013). The good, the bad and the ugly: Perceptions of wildlife in Tombali (Guinea-Bissau, West Africa). Journal of Primatology, 2. https://doi.org/10.4172/2167-6801.1000110.

Delibes, M. (2013). Negative attitudes towards predators do not necessarily result in their killing. Oryx, 48, 16.

Dickman, A. J., Hazzah, L., Carbone, C., \& Durant, S. M. (2014). Carnivores, culture and 'contagious conflict': Multiple factors influence perceived problems with carnivores in Tanzania's Ruaha landscape. Biological Conservation, 178, 19-27.

Dixon, A. B., Hailu, A., Semu, T., \& Taffa, L. (2009). Local responses to marginalisation: Human-wildlife conflict in Ethiopia's wetlands. Geography, 94, 38-47.

Dore, K. M. (2017). Navigating the methodological landscape: Ethnographic data expose the nuances of the Monkey Problem in St. Kitts, West Indies. In K. M. Dore, E. P. Riley, \& A. Fuentes (Eds.), Ethnoprimatology: a practical guide to research at the human-nonhuman primate interface (pp. 219231). Cambridge: Cambridge University Press.

Dore, K. M. (2018). Ethnoprimatology without conservation: The political ecology of farmer-vervet monkey (Chlorocebus aethiops sabaeus) relations in St. Kitts, West Indies. International Journal of Primatology, 39, 918-944.

Dore, K. M., Eller, A. R., \& Eller, J. L. (2018). Identity construction and symbolic association in farmer-vervet monkey (Chlorocebus aethiops sabaeus) interconnections in St. Kitts. Folia Primatologica, 89, 63-80.

El Abdellaoui, M. C. (1999). Explotacion de los recursos naturales. In J. Nogue \& J. L. Villanova (Eds), Espana en Marruecos (pp 511-550). Leida: Editorial Milenio.

Foltz, R. C. (2006). Animals in Islamic tradition and Muslim cultures. Oxford: Oneworld Publications.

Fooden, J. (2007). Systematic review of the Barbary macaque, Macaca sylvanus (Linnaeus, 1758). Fieldiana Zoology, 113, 1-58.

Gogoi, M. (2018). Emotional coping among communities affected by wildlife-caused damage in north-east India: Opportunities for building tolerance and improving conservation outcomes. Oryx, 50, 214-219. 
Goudsmit, J., \& Brandon-Jones, D. (2000). Evidence from the Baboon Catacomb in North Saqqara for a West Mediterranean monkey trade route to Ptolemaic Alexandria. Journal of Egyptian Archaeology, 86, 111-119.

Gray, M. (2014). Farmers' perception of crop-feeding Barbary macaques (Macaca sylvanus) in the Ourika Valley, High Atlas Mountains, Morocco. Master's thesis, Oxford Brookes University.

Hardwick, J. L., Priston, N. E. C., Martin, T. E., Tosh, D. G., Mustari, A. H., \& Abernethy, K. E. (2017). Community perceptions of the crop-feeding Buton macaque (Macaca ochreata brunnescens): An ethnoprimatological study on Buton Island, Sulawesi. International Journal of Primatology, 38, 1102-1119.

Hill, C. M. (1997). Crop-raiding by wild vertebrates: The farmer's perspective in an agricultural community in western Uganda. International Journal of Pest Management, 43, 77-84.

Hill, C. M. (2005). People, crops and primates: A conflict of interests. In J. Patterson \& J. Wallis (Eds.), Commensalism and conflict: the primate-human interface (pp. 40-59). Norman: American Society of Primatology.

Hill, C. M. (2015). Perspectives of "conflict" at the wildlife-agriculture boundary: 10 years on. Human Dimensions of Wildlife, 20, 296-301.

Hill, C. M. (2017). Primate crop feeding behavior, crop protection, and conservation. International Journal of Primatology, 38, 385-400.

Hill, C. M., \& Webber, A. D. (2010). Perceptions of nonhuman primates in human-wildlife conflict scenarios. American Journal of Primatology, 72, 919-924.

Hill, C. M., Webber, A. D., \& Priston, N. E. C. (2017). Understanding conflicts about wildlife: A biosocial approach. Studies of the Biosocial Society. Oxford: Berghahn Books.

Hockings, K. J., MacLennan, M. R., Carvalho, S., Ancranez, M., Bobe, R., et al (2015). Apes in the Anthropocene: Flexibility and survival. Trends in Ecology \& Evolution, 30, 215-222.

Hofner, A. N., Jost-Robinson, C. A., \& Nekaris, K. A. I. (2018). Preserving Preuss's red colobus (Piliocolobus preussi): An ethnographic analysis of hunting, conservation and changing perceptions of primates in Ikenge-Bakoko, Cameroon. International Journal of Primatology, 39, 895-917.

Jost-Robinson, C. A. (2017). Introduction to part III. In K. M. Dore, E. P. Riley, \& A. Fuentes (Eds.), Ethnoprimatology: a practical guide to research at the human-nonhuman primate interface (pp. 253256). Cambridge: Cambridge University Press.

Knight, J. (2003). Waiting for wolves in Japan. Oxford: Oxford University Press.

Knight, J. (2017). Introduction to Part II. In K. M. Dore, E. P. Riley, \& A. Fuentes (Eds.), Ethnoprimatology: A practical guide to research at the human-nonhuman primate interface (pp. 171-175). Cambridge: Cambridge University Press.

Lee, P. C., \& Priston, N. E. C. (2005). Human attitudes to primates: Perceptions of pests, conflict and consequences for primate conservation. In J. D. Paterson \& J. Wallis (Eds.), Commensalism and conflict: the human-primate interface (pp. 1-23). Winnipeg: Higwell Printing.

Linkie, M., Dinata, Y., Nofrianto, A., \& Leader-Williams, N. (2007). Patterns and perceptions of wildlife cropraiding in and around Kerinci Seblat National Park, Sumatra. Animal Conservation, 10, 127-135.

Madden, F., \& McQuinn, B. (2014). Conservation's blind spot: The case for conflict transformation in wildlife conservation. Biological Conservation, 178, 97-106.

Madden, F., \& McQuinn, B. (2017). Conservation conflict transformation: Addressing the missing link in wildlife conservation. In C. M. Hill, A. D. Webber, \& N. E. C. Priston (Eds.), Understanding conflicts about wildlife: a biosocial approach (pp. 148-169). Oxford: Berghahn.

Marechal, L., Semple, S., Majolo, B., \& MacLarnon, A. (2016). Assessing the effects of tourist provisioning on the health of wild Barbary macaques in Morocco. PLOS ONE, 11. https://doi.org/10.1371/journal.pone.0155920.

Margulies, J. D., \& Karanth, K. K. (2018). The production of human-wildlife conflict: A political animal geography of encounter. Geoforum, 95, 153-164.

Marshall, A. J., Nardiyono Engstrom, L. M., Pamungas, B., Meijaard, J. P., \& Stanley, S. A. (2006). The blowgun is mightier than the chain-saw in determining population density of Bornean orang-utans (Pongo pygmaeus morio) in the forest of east Kalimantan. Biological Conservation, 129, 566-578.

McKinney, T. (2015). A classification system for describing anthropogenic influence on nonhuman primate populations. American Journal of Primatology, 77, 715-726.

Mehlman, P. T. (1984). Aspects of the ecology and conservation of the Barbary macaque in the fir forest habitat of the Moroccan Rif Mountains. In J. E. Fa (Ed.), The Barbary macaque: a case study in conservation (pp. 165-199). London: Plenum Press.

Namous, S., \& Znari, M. (2018). Home range and habitat use of crop-raiding Barbary macaques in the Upper Ourika Vally, Western High Atlas Mountains, Morocco. International Journal of Avian \& Wildlife Biology, 3, 36-39.

Parathian, H. E., McLennan, M. R., Hill, C. M., Farazao-Moreira, A., \& Hockings, K. J. (2018). Breaking through disciplinary barriers: Human-wildlife interactions and multispecies ethnography. International Journal of Primatology, 39, 749-775. 
Peterson, J. V., \& Riley, E. P. (2013). Monyet yang dihargai, monyet yang dibenci: the human-macaque interface in Indonesia. In S. Radhakrishna, M. A. Huffman, \& A. Sinha (Eds.), The macaque connection: cooperation and conflict between humans and macaques (pp. 149-166). London: Springer.

Peterson, J. V., Riley, E. P., \& Oka, N. P. (2015). Macaques and the ritual production of sacredness among Balinese transmigrants in South Sulawesi, Indonesia. American Anthropologist, 117, 71-85.

Radford, L., Alexander, S., \& Waters, S. (2018). On the rocks: Using discourse analysis to examine relationships between Barbary macaques (Macaca sylvanus) and people on Gibraltar. Folia Primatologica, 89, 30-44.

Richard, A. F., Goldstein, S. J., \& Dewar, R. E. (1989). Weed macaques: The evolutionary implications of macaque feeding ecology. International Journal of Primatology, 10, 569-594.

Richards, P. (2000). Chimpanzees as political animals in Sierra Leone. In J. Knight (Ed.), Natural enemies (pp. 78-103). London: Routledge.

Riley, E. P. (2007). The human-macaque interface: Conservation implications of current and future overlap and conflict in Lore Lindu National Park, Sulawesi, Indonesia. American Anthropologist, 109, 473-484.

Riley, E. P. (2010). The importance of human-macaque folklore for conservation in Lore Lindu National Park, Sulawesi, Indonesia. Oryx, 44, 235-240.

Saraswat, R., Sinha, A., \& Radhakrishna, S. (2015). A god becomes a pest? Human-rhesus macaque interactions in Himachal Pradesh, northern India. European Journal of Wildlife Research, 61, 435-443.

Schilaci, M. A., Engel, G. A., Fuentes, A., Rompis, A., Putra, A., et al (2010). The not-so-sacred monkeys of Bali: A radiographic study of human-primate commensalism. In S. Gursky-Doyen \& J. Supriatna (Eds.), Indonesian primates (pp. 249-256). Developments in Primatology: Progress and Prospects. New York: Springer Science+Business Media.

Setchell, J. M., Fairet, E. F. M., Shutt, K., Waters, S., \& Bell, S. (2017). Biosocial conservation: Integrating biological and ethnographic methods to study human-primate interactions. International Journal of Primatology, 35, 401-426.

Sprague, R. S., \& Draheim, M. M. (2015). Hawaiian monk seals: Labels, names and stories in conflict. In M. M. Draheim, F. Madden, J.-B. McCarthy, \& E. C. M. Parsons (Eds.), Human-wildlife conflict: complexity in the marine environment (pp. 117-136). Oxford: Oxford University Press.

St John, F. A. V., Edwards-Jones, G., \& Jones, J. P. G. (2010). Conservation and human behaviour: Lessons from social psychology. Wildlife Research, 37, 658-667.

Tadie, D., \& Fischer, A. (2013). Hunting, social structure and human-nature relationships in Lower Omo, Ethiopia: People and wildlife at a crossroads. Human Ecology, 41, 447-457.

Thach, H. M., Le, M. D., Vu, N. B., Panariello, A., Sethi, G., et al (2018). Slow loris trade in Vietnam: Exploring diverse knowledges and values. Folia Primatologica, 89, 45-62.

Treves, A. (2008). The human dimensions of conflicts with wildlife around protected areas. In M. J. Manfredo, J. J. Vaske, P. J. Brown, D. J. Decker, \& E. A. Duke (Eds.), Wildlife and society: the science of human dimensions (pp. 214-228). Washington, DC: Island Press.

Venktess, K. (2015). Painted monkey rescued in Kloof undergoing treatment. Durban: The Witness News24.com.

Wallace, G. E., \& Hill, C. M. (2017). Engaging farmers and understanding their behaviour to develop effective deterrents to crop damage by wildlife. In C. M. Hill, A. D. Webber, \& N. E. C. Priston (Eds.), Understanding conflicts about wildlife: A biosocial approach (pp. 170-193). Oxford: Berghahn.

Waters, S., Bell, S., \& Setchell, J. M. (2018a). Understanding human-animal relations in the context of primate conservation: A multispecies ethnographic approach in North Morocco. Folia Primatologica, 89, 13-29.

Waters, S., Watson, T., Bell, S., \& Setchell, J. M. (2018b). Communicating for conservation: circumventing conflict with communities over domestic dog ownership in North Morocco. European Journal of Wildlife Research, 64. https://doi.org/10.1007/s10344-0181230x.

Waylen, K. A., McGowan, P. J. K., Pawi Study Group, \& Milner-Gulland, E. J. (2009). Ecotourism positively affects awareness and attitudes but not conservation behaviours: A case study at Grande Riviere, Trinidad. Oryx, 43, 343-351.

Wheatley, B. P., Stephenson, R., Kurashina, H., \& Marsh-Kautz, K. G. (2002). A cultural primatological study of Macaca fascicularis on Ngeaur Island, Republic of Pilau. In A. Fuentes \& L. D. Wolfe (Eds.), Primates face to face (pp. 240-253). Cambridge: Cambridge University Press.

Yeo, J.-H., \& Neo, H. (2010). Monkey business: Human-animal conflicts in urban Singapore. Social \& Cultural Geography, 11, 681-699. 